\title{
De Novo Extra-Thyroidal Manifestations of Graves' Disease presenting 16 Years after Total Thyroidectomy for Thyroid Cancer
}

\author{
Ann Kwee,1 Kai-Ling Yong, ${ }^{2}$ Lay Leng Seah, ${ }^{2}$ Chiaw-Ling Chng ${ }^{1}$ \\ ${ }^{1}$ Department of Endocrinology, Singapore General Hospital \\ ${ }^{2}$ Oculoplastics Department, Singapore National Eye Center
}

\begin{abstract}
We present a 61-year-old Chinese female who had a history of angioinvasive follicular thyroid cancer (FTC) treated with total thyroidectomy 16 years ago, without radioactive iodine (RAI) treatment who now presents with de novo pretibial myxedema (PTM) followed by active severe Graves' ophthalmopathy (GO) requiring pulse steroids and radiotherapy.
\end{abstract}

Key words: thyroid cancer, Graves' disease, thyroidectomy, radioactive iodine

\section{INTRODUCTION}

There have been very few reports of extrathyroidal manifestations of Graves' Disease (GD) after a total thyroidectomy, without radioactive iodine (RAI) treatment. In this case, our patient presented 16 years post total thyroidectomy with extrathyroidal manifestations. This case underscores the occasional difficulty in diagnosis of extrathyroidal manifestations in the absence of hyperthyroidism. Furthermore, it emphasizes the point that presence of thyroid stimulating hormone receptor antibodies (TRAb) are risk factors for extrathyroidal manifestations of GD.

\section{CASE}

Our patient is a Chinese female, non-smoker, who presented at age 43 years old with an incidental finding of a non-obstructive anterior neck mass. A fine needle aspiration biopsy was performed on the left thyroid nodule, which showed a follicular neoplasm. She proceeded with a total thyroidectomy and was found to have a $3.0 \times 2.5$ $\mathrm{cm}$ minimally invasive FTC with capsular and possible angioinvasion (TNM staging T2N0M0, Stage 1). There was no histological evidence of hyperplasia or hypertrophy of the remaining thyroid follicular cells to suggest possible Graves' disease (GD). The post-operative recovery was complicated by secondary hypoparathyroidism. No remnant RAI ablation was performed post-operatively.

Her significant medical history included diabetes mellitus, hypertension, and hyperlipidemia on treatment. Notably, her sister had hyperthyroidism, while her brother had hypothyroidism, both likely related to autoimmune thyroid disease. There was no family history of thyroid cancer. Medications after surgery included levothyroxine (LT4) $100 \mathrm{mcg}$ on weekdays and $125 \mathrm{mcg}$ on weekends (total $750 \mathrm{mcg} /$ week), calcitriol $0.25 \mathrm{mcg}$ OD, calcium carbonate
$600 \mathrm{mg}$ on weekdays and $1200 \mathrm{mg}$ on weekends. She was subsequently followed up in another institution.

In May 2016, she consulted a dermatologist for bilateral non-resolving, red, swollen, and itchy skin lesions on her lower limbs which had been present for a year. Cutaneous examination revealed presence of multiple skin-colored firm nodules over both shins, ranging in sizes from 1-2 cm in diameter. The underlying area was hyperpigmented up to mid-shin (Figure 1). This was initially diagnosed as eczema by her general practitioner prior to the consult. She was treated with multiple rounds of topical steroids and emollients without improvement. A left shin punch biopsy showed dermal mucinosis, consistent with pre-tibial myxedema (PTM). This was treated with intralesional steroid injections. There were no nail findings.
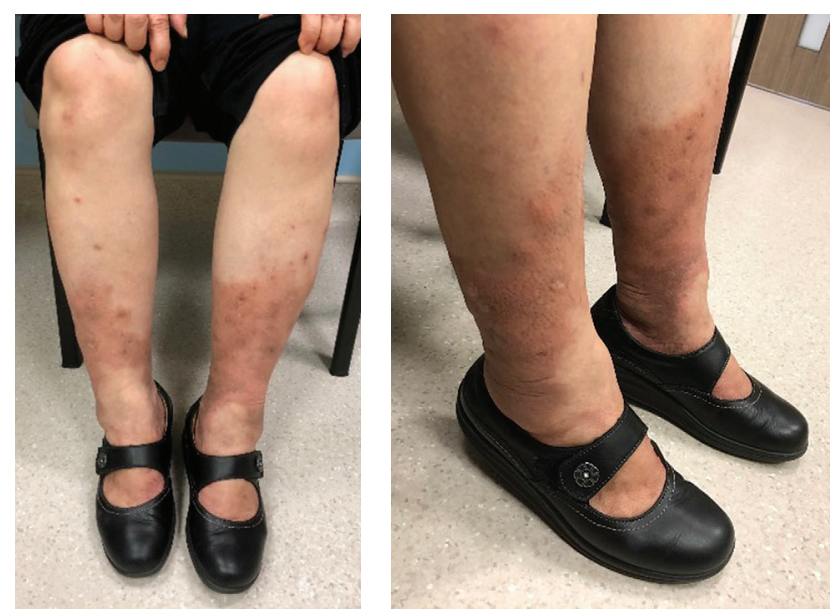

Figure 1. Images of the patient's pre-tibial myxedema (2018). Multiple skin-colored nodules and hyperpigmented plaques with 'peau d'orange appearance' over both shins. 


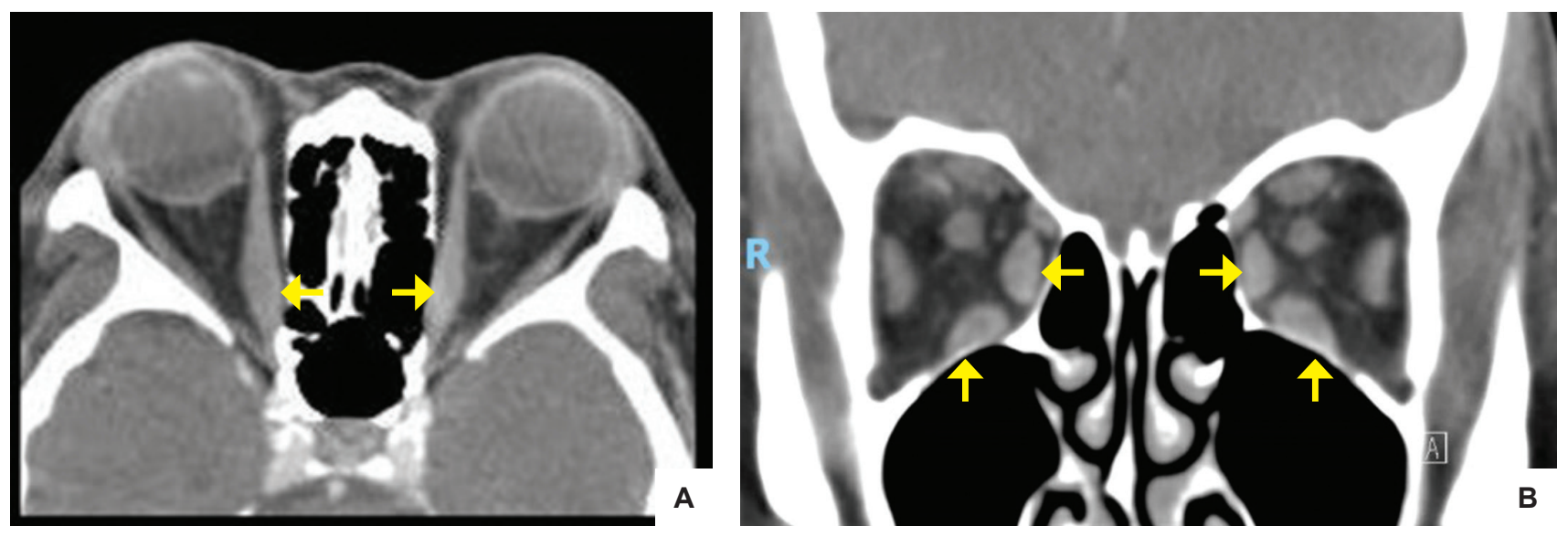

Figure 2. CT scan of the orbits at presentation of GO with (A) axial and (B) coronal views (2017). Bilateral proptosis, bulky inferior and medial rectus muscles (arrows) with medial deviation of the right eye globe. Optic nerves are stretched without compression.

In August 2017 (a year after diagnosis of PTM), our patient began experiencing intermittent binocular diplopia while driving. She also noticed bilateral eye redness and itchiness. There was no eye pain, tearing, grittiness or photophobia. On examination, she had bilateral periorbital swelling with redness, worse on the left, conjunctival injection, chemosis, exophthalmos, limitation of eye movements in all directions of gaze, especially on abduction and elevation bilaterally but without lagophthalmos. Computed Tomography (CT) imaging of her orbits showed mild bilateral proptosis with medial deviation of the right eye globe, enlarged extraocular muscles, increased fat stranding, and stretched bilateral optic nerves without compression (Figure 2). A diagnosis of active severe $\mathrm{GO}$ was made (based on EUGOGO classification). ${ }^{1}$ Prior to seeing us, she had been consulting endocrinologists from various institutions and was noticed to have fluctuating thyroid function results requiring adjustments of her thyroxine dosage. During the initial consultation at our institution, she was observed to have an increasing thyroglobulin ( $\mathrm{Tg}$ ) trend and increasingly deranged thyroid function despite reported medication compliance. Her thyroid function results from 2010 till her consultation in our institution in 2017 are summarized in Table 1.

We had a thorough discussion with the patient about undergoing a radioactive iodine whole body scan (RAI WBS) versus a technetium-99 (Tc-99) thyroid scan and ultrasound for detection of possible local thyroid cancer recurrence that might explain the rising Tg levels. We acknowledge that Tc-99 scan is unable to detect distant follicular thyroid carcinoma metastasis, but the patient had stage 1 follicular thyroid carcinoma more than 20 years ago with exceptionally good prognosis and the possibility of distant metastases at this point was quite low. The patient was not keen for RAI WBS despite the rare likelihood of GO activation.

An ovoid, well circumscribed hypoechoic solid lesion (0.9 $x 0.5 \times 1.1 \mathrm{~cm})$ at the midline anterior neck and superficial to the thyroid cartilage was seen on the Tc-99 thyroid scan and ultrasound. This lesion also corresponded to a focus of intense tracer uptake on scintigraphy (Figure 3). No abnormal cervical lymphadenopathy was seen. An ultrasound guided fine needle aspirate of the thyroid lesion showed cytology of benign nodular goiter. It is interesting that her thyroid stimulating receptor antibody (TRAb) level was also elevated at 35.8 IU/L [Normal Range (NR) 0.0-1.5].

Our patient was treated with pulsed intravenous methylprednisolone (1g for 3 days) followed by fractionated orbital radiation. She showed improvement of her orbital congestion and ocular motility function. Her PTM had resolved after a course of intralesional steroid injections. At her most recent review in 2020, her $\mathrm{Tg}$ level had decreased to $1.1 \mathrm{Ug} / \mathrm{L}$ (NR 1.6-50), FT4 was within normal

Table 1. Thyroglobulin (Tg), Anti-Thyroglobulin Antibody (TgAb), free T4 (fT4), thyroid stimulating hormone (TSH) trends of the patient after thyroidectomy until her presentation to our institution

\begin{tabular}{|c|c|c|c|c|c|}
\hline & $\begin{array}{l}\mathrm{Tg} \\
(2.0-70.0 \mathrm{ug} / \mathrm{L})\end{array}$ & $\begin{array}{l}\text { TgAb } \\
(0-60 \mathrm{u} / \mathrm{mL})\end{array}$ & $\begin{array}{l}\mathrm{fT} 4 \\
(8.8-14.4 \mathrm{pmol} / \mathrm{L}) \\
\end{array}$ & $\begin{array}{l}\text { TSH } \\
(0.65-3.70 \mathrm{mu} / \mathrm{L}) \\
\end{array}$ & $\begin{array}{l}\text { Oral LT4 cumulative } \\
\text { weekly dose (mcg) }\end{array}$ \\
\hline $2^{\text {nd }}$ June 2010 & $<0.17 \downarrow$ & $<10$ & $20.9 \uparrow$ & $0.159 \downarrow$ & 1050 \\
\hline $10^{\text {th }}$ Sep 2012 & $1.0 \downarrow$ & $<10$ & $23.4 \uparrow$ & $0.254 \downarrow$ & 875 \\
\hline $4^{\text {th }}$ Feb 2013 & $1.4 \downarrow$ & $<10$ & $21.9 \uparrow$ & $0.147 \downarrow$ & 875 \\
\hline \multirow[t]{2}{*}{$20^{\text {th }}$ Mar 2014} & $1.2 \downarrow$ & $<10$ & $21.3 \uparrow$ & 0.710 & 700 \\
\hline & $\begin{array}{l}\mathrm{Tg} \\
(1.6-61 \mathrm{ug} / \mathrm{L})\end{array}$ & $\begin{array}{l}\text { TgAb } \\
(0-40 \mathrm{u} / \mathrm{mL})\end{array}$ & $\begin{array}{l}\text { fT4 } \\
(12-22 \mathrm{pmol} / \mathrm{L})\end{array}$ & $\begin{array}{l}\text { TSH } \\
(0.27-4.20 \mathrm{mu} / \mathrm{L})\end{array}$ & $\begin{array}{l}\text { Oral LT4 cumulative } \\
\text { weekly dose (mcg) }\end{array}$ \\
\hline $8^{\text {th }}$ Jul 2015 & 2.6 & $<20$ & $27.3 \uparrow$ & $1.11 \downarrow$ & 725 \\
\hline \multirow[t]{2}{*}{$16^{\text {th }}$ Feb 2016} & 3.0 & $<20$ & $24.1 \uparrow$ & $5.97 \uparrow$ & 725 \\
\hline & $\begin{array}{l}\mathrm{Tg} \\
(2.0-70.0 \mathrm{ug} / \mathrm{L})\end{array}$ & $\begin{array}{l}\text { TgAb } \\
(0-60 \mathrm{u} / \mathrm{mL})\end{array}$ & $\begin{array}{l}\text { fT4 } \\
(8.8-14.4 \mathrm{pmol} / \mathrm{L})\end{array}$ & $\begin{array}{l}\text { TSH } \\
(0.65-3.70 \mathrm{mu} / \mathrm{L})\end{array}$ & $\begin{array}{l}\text { PO LT4 cumulative } \\
\text { weekly dose }(\mathrm{mcg})\end{array}$ \\
\hline $6^{\text {th }}$ Oct 2017 & 3.5 & $<10$ & $18.8 \uparrow$ & $4.50 \uparrow$ & 750 \\
\hline
\end{tabular}



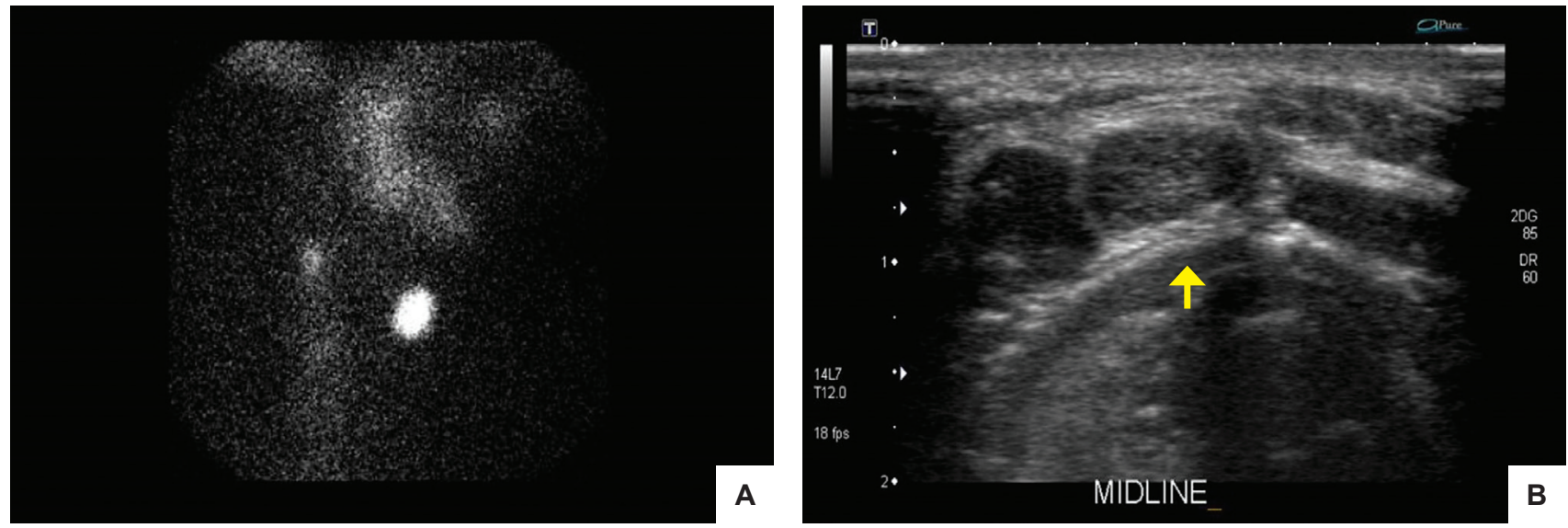

Figure 3. Tc-99 scintigraphy (A) and thyroid ultrasound (B) in 2017 showed a focus of intense radiotracer uptake at the anterior midline neck corresponding to a solid hypoechoic lesion (arrow) superficial to the thyroid cartilage.

at $19.4 \mathrm{pmol} / \mathrm{L}$ (NR 8.8-14.4), TSH was likewise normal at $1.46(0.65-3.70 \mathrm{mU} / \mathrm{L})$, and TRAb was negative.

\section{DISCUSSION}

There are acknowledged links between GD and thyroid cancer, with mechanisms postulated being TSH receptor antibodies stimulating thyroid cancer growth over time and the direct carcinogenic effects of GD. ${ }^{2-5}$ In patients with GD, a higher incidence of thyroid nodules and cancer $(2.3-46 \%)$ has been reported, compared to the general population. ${ }^{6-10}$ There have been cases of concurrent GD and metastatic thyroid carcinoma implying that TRAb may act as a promoter in the pathogenesis of thyroid cancer. ${ }^{5}$ However, a case such as our patient is novel and has not been previously been reported in literature, when thyroid cancer presents before GD.

Despite having undergone a total thyroidectomy, our patient developed extra-thyroidal manifestations of GD. Although there have been case reports of euthyroid patients without a previous history of hyperthyroidism who developed signs of $\mathrm{GO}^{11-13}$ our patient presented with a long latency period of 16 years post total thyroidectomy with PTM and GO. There are fewer than 10 cases reported in the literature so far of GD developing after thyroidectomy for nodules or cancer. ${ }^{14-17}$ Notably, the occurrence of de novo GO in patients with thyroid cancer after total thyroidectomy without RAI such as in our patient's case has not been reported.

Clinical and genetic observations support the concept that GO, PTM and Graves' hyperthyroidism are manifestations of the same autoimmune disease. ${ }^{3}$ It follows, therefore, that all components of the clinical triad may stem from an immune reaction directed against the same or a similar autoantigen. ${ }^{3}$ The presence of TRAb is central to the pathogenesis of all three related entities. The complete surgical removal of the thyroid gland should theoretically obliterate the risk of development of these manifestations since it avoids worsening of thyroid humoral autoimmunity by removing thyroid antigens and intra-thyroidal autoreactive $\mathrm{T}$ lymphocytes. ${ }^{13}$ However, our patient still had evidence of a thyroid remnant, most likely arising from the pyramidal lobe that was overlooked at the time of surgery.
Nonetheless, a study by Marcocci et al., has shown that a near-total thyroidectomy does not modify the course of GO. ${ }^{18}$ There have been previous case reports of GD being diagnosed biochemically following thyroidectomy, with variable latent time to manifestation (3-120 months, median 48 months). ${ }^{11,14-17}$ It has been postulated that the persistence of even minimal residual thyroid can have a role in maintaining orbit autoimmune phenomena since antigen triggers could originate from minuscule amounts of thyroid tissue left behind. ${ }^{18,19}$ In addition, even though evidence suggests that the thyroid gland is a major site of TSH receptor antibody synthesis in GD, other sites of TRAb synthesis should be considered..$^{20,21}$ TSH receptors are present in both normal and Graves' orbital tissues. Therefore, it is theoretically possible that orbital tissues were the sources of the antigen. ${ }^{22}$ There are data to suggest that TSH receptors are likely present in fibroblasts in the anterior tibial region, explaining the genesis of the pretibial myxedema. ${ }^{23}$ Some patients with subtotal thyroidectomies have had persistent thyroid antibodies postoperatively, suggesting that other sites of thyroid autoantibody synthesis may also exist. ${ }^{20,21}$

There was no co-occurrence of GD and thyroid cancer prior to thyroidectomy in our patient since there was no biochemical or histological evidence of GD pre-operatively. The presence of functional FTC metastasis contributing to the development of TRAb leading to extra-thyroidal manifestations in our patient is also unlikely since she remained euthyroid on thyroxine replacement and $\mathrm{Tg}$ levels were on a declining trend following treatment of her GO. On hindsight, the initial rising Tg trend may be related to development of TRAb and may have been exacerbated by rising TSH levels possibly attributed to the patient occasionally mixing her thyroxine with her meals and calcium supplementation. The elevated TSH was likely due to drug interactions that affected gastrointestinal absorption. The high fT4 could have been due to the erratic intake of thyroxine with respect to timing of the blood investigations.

Hence, we postulate that the development of PTM and GO in our patient was related to the remnant thyroid tissue post total thyroidectomy, which may have triggered thyroid autoimmunity, and led to further perpetuation of the autoimmune cascade over a long latent 
period, with eventual presentation of these extrathyroidal manifestations.

\section{CONCLUSION}

We describe an unusual case of a patient who presented with severe active GO and PTM 16 years after total thyroidectomy for a minimally invasive follicular thyroid cancer. We postulate that the presence of remnant thyroid tissue post-surgery triggered the development of TRAb which led to the severe extra-thyroidal manifestations in this patient. Clinicians should be aware of the possible occurrence of extra-thyroidal manifestations even after total thyroidectomy.

\section{Ethical Consideration}

Patient consent was obtained before submission of the manuscript.

\section{Statement of Authorship}

All authors certified fulfilment of ICMJE authorship criteria.

\section{Author Disclosure}

The authors declared no conflict of interest.

\section{Funding Source}

None.

\section{References}

1. Bartalena L, Baldeschi L, Boboridis K, et al. The 2016 European Thyroid Association/European Group on Graves' Orbitopathy Guidelines for the Management of Graves' Orbitopathy. Eur Thyroid J. 2016;5(1):9-26. PMID: 27099835. PMCID: PMC4836120. https://doi. org/10.1159/000443828.

2. Laurberg P, Wallin G, Tallstedt L, Abraham-Nordling M, Lundell G, Törring O. TSH-receptor autoimmunity in Graves' disease after therapy with anti-thyroid drugs, surgery, or radioiodine: A 5-year prospective randomized study. Eur J Endocrinol. 2008;158(1):69-75. PMID: 18166819. https://doi.org/10.1530/EJE-07-0450

3. Bahn RS. Clinical review 157 - Pathophysiology of Graves' ophthalmopathy: The cycle of disease. I Clin Endocrinol Metab. 2003;88(5):1939-46. PMID: 12727937. https://doi.org/10.1210/jc.2002030010 .

4. Folkestad L, Brandt F, Brix T, et al. Total Thyroidectomy for thyroid cancer followed by thyroid storm due to thyrotropin receptor antibody stimulation of metastatic thyroid tissue. Eur Thyroid J. 2017;6(5):276-80. PMID: 29071241. PMCID: PMC5649237. https:// doi.org/10.1159/000479061.

5. Filetti S, Belfiore A, Amir SM, et al. The role of thyroid-stimulating antibodies of Graves' disease in differentiated thyroid cancer. N Engl J Med. 1988;318(12):753-9. PMID: 3347223. https://doi. org/10.1056/NEJM198803243181206.

6. Dobyns B, Sheline G, Workman J, Tompkins E, McConahey W, Becker D. Malignant and benign neoplasms of the thyroid in patients treated for hyperthyroidism: A report of the cooperative thyrotoxicosis therapy follow-up study. J Clin Endocrinol Metab. 1974;38(6):978-98. PMID: 4134013. https://doi.org/10.1210/jcem-38-6-976.

7. Chen YK, Lin CL, Chang YJ, et al. Cancer risk in patients with Graves disease: A nationwide cohort study. Thyroid. 2013:23(7):879-84. PMID: 23421548. PMCID: PMC3704114. https://doi.org/10.1089/thy.2012.0568.
8. Pazaitou-Panayiotou K, Perros P, Boudina M, et al. Mortality from thyroid cancer in patients with hyperthyroidism: The Theagenion Cancer Hospital experience. Eur J Endocrinol. 2008;159(6):799-803. PMID: 18819945. https://doi.org/10.1530/EJE-08-0468.

9. Belfiore A, Russo D, Vigneri R, Filetti S. Graves' disease, thyroid nodules and thyroid cancer. Clin Endocrinol (Oxf). 2001;55(6):711-8. PMID: 11895209. https://doi.org/10.1046/j.1365-2265.2001.01415.x.

10. RossDS, Burch HB, Cooper DS, et al. 2016 American Thyroid Association Guidelines for diagnosis and management of hyperthyroidism and other causes of thyrotoxicosis. Thyroid. 2016;26(10):1343-421. PMID: 27521067. https://doi.org/10.1089/thy.2016.0229.

11. Jang SY, Lee KH, Oh JR, Kim BY, Yoon JS. Development of thyroidassociated ophthalmopathy in patients who underwent total thyroidectomy. Yonsei Med J. 2015;56(5):1389-94. PMID: 26256985. PMCID: PMC4541672. https://doi.org/10.3349/ymi.2015.56.5.1389

12. Yoon JS, Lew H, Park JS, Nam KH LS. Papillary thyroid carcinoma with thyroid-associated orbitopathy in a euthyroid state. Ophthalmic Plast Reconstr Surg. 2007;23(3):187-91. PMID: 17519654. https://doi. org/10.1097/IOP.0b013e31803e1755.

13. Eckstein AK, Lösch C, Glowacka D, et al. Euthyroid and primarily hypothyroid patients develop milder and significantly more asymmetrical Graves ophthalmopathy. $\mathrm{Br}$ J Ophthalmol. 2009;93(8):1052-6. PMID: 19221109. https://doi.org/10.1136/bjo. 2007.137265.

14. Tamai H, Hirota Y, Matsuzuka F, Kuma K NS. Three cases developed Graves' disease after surgical treatment for thyroid carcinomas. Horumon To Rinsho. 1982;30:124-5.

15. Yu HM, Park SH, Lee JM, Park KS. Graves' disease that developed shortly after surgery for thyroid cancer. Endocrinol Metab (Seoul). 2013;28(3):226-30. PMID: 24396683. PMCID: PMC3811703. https:// doi.org/10.3803/enm.2013.28.3.226.

16. Misaki T, Iwata M, Kasagi K, et al. Hyperthyroid Graves' disease after hemithyroidectomy for papillary carcinoma: Reort of Three Cases. Endocr J. 2000;47(2):191-5. PMID: 10943744. https://doi.org/10.1507/ endocri.47.191.

17. Kasuga Y, Kobayashi S, Fujimori M, et al. Development of Graves' disease after surgical treatment for thyroid nodules: Report of four cases. Endocr J. 1997;44(4):567-70. PMID: 9447291. https://doi org $/ 10.1507 /$ endocri.44.567

18. Marcocci C, Bruno-Bossio G, Manetti L, et al. The course of Graves' ophthalmopathy is not influenced by near total thyroidectomy: A case-control study. Clin Endocrinol (Oxf). 1999;51(4):503-8. PMID: 10583319. https://doi.org/10.1046/j.1365-2265.1999.00843.x.

19. De Bellis A, Conzo G, Cennamo G, et al. Time course of Graves' ophthalmopathy after total thyroidectomy alone or followed by radioiodine therapy: A 2-year longitudinal study. Endocrine. 2012;41(2):320-6. PMID: 22169963. https://doi.org/10.1007/s12020-0119559-x.

20. Cho BY, Oh SK, Shong YK, et al. Changes in thyrotropin receptor antibody after subtotal thyroidectomy in Graves' disease: Comparison with the degree of lymphocytic infiltration in the thyroid. Autoimmunity. 1990;8(2):143-7. PMID: 1983330. https://doi. org $/ 10.3109 / 08916939008995732$

21. De Bruin TWA, Patwardhan NA, Brown RS, Braverman LE. Graves disease: Changes in TSH receptor and anti-microsomal antibodies after thyroidectomy. Clin Exp Immunol. 1988;72(3):481-5. PMID: 3168323. PMCID: PMC1541569.

22. Garrity JA, Bahn RS. Pathogenesis of Graves ophthalmopathy: Implications for prediction, prevention, and treatment. Am J Ophthalmol. 2006;142(1):147-53. PMID: 16815265. PMCID: PMC3960010. https://doi.org/10.1016/j.ajo.2006.02.047.

23. Fatourechi V. Pretibial myxedema pathophysiology and treatment options. Am J Clin Dermatol. 2005;6(5):295-309. PMID: 16252929. https://doi.org/10.2165/00128071-200506050-00003.

Authors are required to accomplish, sign and submit scanned copies of the JAFES Author Form consisting of: (1) Authorship Certification, that authors contributed substantially to the work, that the manuscript has been read and approved by all authors, and that the requirements for authorship have been met by each author; (2) the Author Declaration, that the article represents original material that is not being considered for publication or has not been published or accepted for publication elsewhere, that the article does not infringe or violate any copyrights or intellectual property rights, and that no references have been made to predatory/suspected predatory journals; (3) the Author Contribution Disclosure, which lists the specific contributions of authors; (4) the Author Publishing Agreement which retains author copyright, grants publishing and distribution rights to JAFES, and allows JAFES to apply and enforce an Attribution-Non-Commercial Creative Commons user license; and (5) the Conversion to Visual Abstracts (*optional for original articles only) to improve dissemination to practitioners and lay readers Authors are also required to accomplish, sign, and submit the signed ICMJE form for Disclosure of Potential Conflicts of Interest. For original articles, authors are required to submit a scanned copy of the Ethics Review Approval of their research as well as registration in trial registries as appropriate. For manuscripts reporting data from studies involving animals, authors are required to submit a scanned copy of the Institutional Animal Care and Use Committee approval. For Case Reports or Series, and Images in Endocrinology, consent forms, are required for the publication of information about patients; otherwise, appropriate ethical clearance has been obtained from the institutional review board. Articles and any other material published in the JAFES represent the work of the author(s) and should not be construed to reflect the opinions of the Editors or the Publisher. 